\title{
Aerosol dynamics simulations on the connection of sulphuric acid and new particle formation
}

\author{
S.-L. Sihto ${ }^{1}$, H. Vuollekoski ${ }^{1}$, J. Leppä ${ }^{2}$, I. Riipinen ${ }^{1}$, V.-M. Kerminen ${ }^{2}$, H. Korhonen ${ }^{3}$, K. E. J. Lehtinen ${ }^{3,4}$, M. Boy $^{1}$, \\ and M. Kulmala ${ }^{1}$ \\ ${ }^{1}$ University of Helsinki, Department of Physics, P.O. Box 64, 00014 University of Helsinki, Finland \\ ${ }^{2}$ Finnish Meteorological Institute, Climate and Global Change, P.O. Box 503, 00101 Helsinki, Finland \\ ${ }^{3}$ University of Kuopio, Department of Physics, P.O. Box 1627, 70211 Kuopio, Finland \\ ${ }^{4}$ Finnish Meteorological Institute, Kuopio Unit, P.O. Box 1627, 70211 Kuopio, Finland
}

Received: 11 April 2008 - Published in Atmos. Chem. Phys. Discuss.: 10 June 2008

Revised: 5 February 2009 - Accepted: 21 February 2009 - Published: 6 May 2009

\begin{abstract}
We have performed a series of simulations with an aerosol dynamics box model to study the connection between new particle formation and sulphuric acid concentration. For nucleation either activation mechanism with a linear dependence on the sulphuric acid concentration, kinetic mechanism with a squared dependence on the sulphuric acid concentration or ternary $\mathrm{H}_{2} \mathrm{O}-\mathrm{H}_{2} \mathrm{SO}_{4}-\mathrm{NH}_{3}$ nucleation was assumed. The aim was to study the factors that affect the sulphuric acid dependence during the early stages of particle growth, and specifically to find conditions which would yield the linear dependence between the particle number concentration at $3-6 \mathrm{~nm}$ and sulphuric acid, as observed in field experiments. The simulations showed that the correlation with sulphuric acid may change during the growth from nucleation size to $3-6 \mathrm{~nm}$ size range, the main reason being the size dependent growth rate between 1 and $3 \mathrm{~nm}$. In addition, the assumed size for the nucleated clusters had a crucial impact on the sulphuric acid dependence at $3 \mathrm{~nm}$. A linear dependence between the particle number concentration at $3 \mathrm{~nm}$ and sulphuric acid was achieved, when activation nucleation mechanism was used with a low saturation vapour pressure for the condensable organic vapour, or with nucleation taking place at $\sim 2 \mathrm{~nm}$ instead of $\sim 1 \mathrm{~nm}$. Simulations with activation, kinetic and ternary nucleation showed that ternary nucleation reproduces too steep dependence on sulphuric acid as compared to the linear or square dependence observed in field measurements.
\end{abstract}

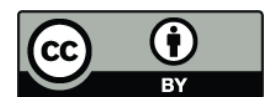

Correspondence to: S.-L. Sihto (sanna-liisa.sihto@helsinki.fi)

\section{Introduction}

Particle formation from gaseous precursors is an important source of particles in the atmosphere. Events of new particle formation starting with nucleation of tiny clusters and followed by growth to bigger, climatically relevant sizes, have been observed all around the world, from remote locations to polluted urban cities (Kulmala et al., 2004a). Regionally, atmospheric particle formation may give a dominant contribution to the total particle number concentration (Spracklen et al., 2006, Tunved et al., 2006) and affect significantly both cloud condensation nuclei and cloud droplet concentrations (Kerminen et al., 2005; Laaksonen et al., 2005; Spracklen et al., 2008).

Aerosol particles affect the climate directly by scattering and absorbing radiation, and indirectly by influencing the cloud formation and by modifying the cloud properties. The aerosol indirect effect is one of the most poorly known factors of the climate system (Penner et al., 2006; Rosenfeld, 2006; IPCC, 2007; Baker and Peter, 2008). Besides the uncertainties associated with aerosol-climate interactions, the mechanism of atmospheric nucleation is still unclear (e.g. Kulmala and Kerminen, 2008). Due to these uncertainties and computational cost of modelling the full aerosol dynamics, most climate models have a very crude representation of aerosol processes. Thus there is a need for detailed understanding of the relevant processes, in order to develop accurate, yet computationally efficient parameterizations applicable to large-scale modeling frameworks.

Field measurements of aerosol particle and sulphuric acid concentrations have shown that atmospheric new particle

Published by Copernicus Publications on behalf of the European Geosciences Union. 
formation seems to be a function of gaseous sulphuric acid concentration to the power of 1-2 (Weber et al., 1996, 1997; Sihto et al., 2006; Riipinen et al., 2007; Kuang et al., 2008). This dependence is in contrast with the theory of ternary sulphuric acid-water-ammonia nucleation (Napari et al., 2002a) which predicts critical cluster sizes of 4-10 molecules, yielding correlation exponents of 4-10 between nucleation rate and sulphuric acid concentration. To explain the observations, nucleation mechanisms known as activation (Kulmala et al., 2006) and kinetic nucleation (McMurry and Friedlander, 1979) have been proposed, with nucleation rate linearly or squarely dependent on sulphuric acid concentration. The activation type nucleation mechanism has been applied in a global aerosol microphysics model (Spracklen et al., 2006), showing very good agreement with measurements performed at SMEAR II station (Hari and Kulmala, 2005) in Hyytiälä, Finland.

Conventional atmospheric particle number concentration measurements start from particle diameter of $3 \mathrm{~nm}$, while actual nucleation, i.e. formation of stable clusters, happens at smaller sizes, well below $3 \mathrm{~nm}$. Recently there have been advances in measuring sub- $3 \mathrm{~nm}$ neutral and charged particles in field (Kulmala et al., 2007), which indicate that atmospheric nucleation starts at $1.5-2 \mathrm{~nm}$ size range. However, the observed correlations with sulphuric acid have so far been done with particle concentrations at 3-6 nm (Sihto et al., 2006; Riipinen et al., 2007). From these dependences for $3 \mathrm{~nm}$ particles, one would like to extrapolate the similar dependence for nucleated clusters. This is not straightforward, since between the nucleation size and $3 \mathrm{~nm}$, particles are subject to size-dependent aerosol dynamical processes: they grow by condensation of sulphuric acid and/or other vapours, and are lost in coagulation with each other and with background aerosol particles (e.g. McMurry, 1983; Kerminen et al., 2004; McMurry et al., 2005). Therefore the dependence of particle formation on sulphuric acid concentration may change as particles grow to larger sizes.

Aerosol dynamical modelling has been widely used to investigate the factors affecting new particle formation events (e.g. Kulmala et al., 1995). Specifically, different nucleation mechanisms have been tested: e.g. ternary nucleation (Gaydos et al., 2005), kinetic nucleation (Laakso et al., 2004), and ion-induced nucleation (Yu et al., 2006). Jung et al. (2008) compared various nucleation theories and found that ternary nucleation best reproduced the occurrence of nucleation events in Pittsburgh. However, in most studies mainly the occurence or lack of a nucleation event has been considered, but less emphasis has been put on the predicted intensity of new particle formation or on the correlations between particle formation rates with gas concentrations.

Here we investigate, using the aerosol dynamical model UHMA (University of Helsinki Multicomponent Aerosol model, Korhonen et al., 2004), the factors that influence the connection between sulphuric acid and new particle formation during the early stages of particle growth. In particular, we aim to find conditions which would yield the observed linear dependence between the particle number concentration and sulphuric acid, and investigate how the dependence on sulphuric acid concentration changes as particles grow from nucleation size to larger sizes.

\section{Modelling approach}

\subsection{UHMA model}

The aerosol dynamics model UHMA (University of Helsinki Multicomponent Aerosol model, Korhonen et al., 2004) is a sectional box model designed to study new particle formation and growth. It has all the basic aerosol microphysical mechanisms for clear sky conditions implemented: nucleation, condensation, coagulation and dry deposition. In previous studies UHMA has been extended to include cloud processing (Korhonen et al., 2005), it has been applied in a Lagrangian trajectory study (Komppula et al., 2006), and it has been implemented as a part of the 1-D columnar model MALTE (Boy et al., 2006). For this study, the basic box-model version of UHMA is sufficient. Here we describe briefly the features of the model relevant to this study; for more details we refer the reader to Korhonen et al. (2004).

In the UHMA model, particles are assumed to consist of sulphuric acid, water, ammonia and an organic modelcompound, and to be internally mixed inside a size section. As input for the model, an initial size distribution, ambient meteorological conditions (temperature, relative humidity) and gas concentrations for the condensing vapours must be given. The model then calculates the evolution of the particle size distribution subject to aerosol dynamical processes.

Condensation and coagulation are calculated according to the conventional equations by Fuchs and Sutugin (1971). However, for condensation in the free-molecular regime we apply a modification by Lehtinen and Kulmala (2003). It takes into account the particle diffusion coefficient and diameter of the condensing molecule, when calculating the particle Knudsen number and coagulation coefficient - these are normally assumed negligible compared to the vapour diffusion coefficient and particle diameter. The modified condensation theory approaches the free-molecular coagulation theory in the limit of free molecular particles. The correction increases the free-molecular regime condensation flux compared to the traditional Fuchs-Sutugin expression, and is significant for particle sizes $d_{p}<10 \mathrm{~nm}$.

In these simulations, we apply two condensing vapours: sulphuric acid and an organic model-compound, which represents the oxidation products of biogenic volatile organic compounds (BVOCs, e.g. monoterpenes). Measurements in boreal forest have shown that sulphuric acid can explain on average only one tenth of the observed growth rate, and the remaining growth rate has been attributed to the organic 
compounds emitted by the forest (Kulmala et al., 2004b; Boy et al., 2005; Hirsikko et al., 2005).

Sulphuric acid production rate is calculated as a chemical reaction rate between $\mathrm{SO}_{2}$ and $\mathrm{OH}$, while the $\mathrm{OH}$ concentration is dependent on the solar zenith angle. This results in a sinusoidal profile for sulphuric acid concentration with a maximum value around noon. The saturation vapour concentration of sulphuric acid is assumed to be negligible, i.e. it condenses with the maximum flux without Kelvin effect $\left(c_{\mathrm{sat}}=0\right)$. Due to this assumption the growth rates by sulphuric acid may be overestimated for the smallest particles, but because sulphuric acid makes only about $25 \%$ of the particle growth, this approximation does not affect our results significantly.

The condensation of a water-soluble, semi-volatile organic vapor is calculated with the nano-Köhler mechanism (Kulmala et al., 2004c; Anttila et al., 2004), which takes into account the Kelvin effect and the solubility effect (Raoult effect), analogously to the traditional Köhler-theory. However, instead of describing the equilibrium of $\mu \mathrm{m}$-sized cloud droplets with water vapour, nano-Köhler theory considers $\mathrm{nm}$-sized clusters, consisting of ammonium bisulphate, organic compound and water, in equilibrium with a watersoluble organic vapour. The equilibrium pressures of the organic vapour $\left(p_{\text {eq,org }}\right)$ and water vapour $\left(p_{\text {eq, } w}\right)$ over a spherical particle are given by the two Köhler-type equations:

$p_{\text {eq,org }}=p_{s, \text { org }} \gamma_{\text {org }} \exp \left(\frac{4 \sigma m_{\text {org }}}{R T \rho_{\mathrm{org}} d_{p}}\right)$,

$p_{\mathrm{eq}, w}=p_{s, w} \gamma_{w} \exp \left(\frac{4 \sigma m_{w}}{R T \rho_{w} d_{p}}\right)$.

The first equation refers to organic vapour (org) and second to water vapour $(w)$. Here $p_{s, \text { org }}\left(p_{s, w}\right)$ is the saturation vapour pressure of pure organic vapour (water) over flat surface, $\gamma_{\text {org }}\left(\gamma_{w}\right)$ the activity coefficient of the organic compound (water), $d_{p}$ the particle diameter, $T$ temperature, $k_{B}$ Boltzmann's constant, $\sigma$ surface tension of the droplet, $m_{\text {org }}$ $\left(m_{w}\right)$ molecular mass and $\rho_{\text {org }}\left(\rho_{w}\right)$ density of the organic compound (water). The two equations must be solved simultaneously. For estimating the activity coefficients and surface tensions, the solution is assumed to behave as pseudobinary, consisting of an organic compound and ammonium bisulphate with the associated water. The volatility of the organic vapor can be varied by changing its saturation vapour pressure $p_{s, \text { org }}$, or saturation vapour concentration $\left(c_{\text {sat,org }}\right)$ which we will use here.

For water vapour and ammonia condensation is not calculated dynamically, but through a parameterization for the equilibrium uptake of water and ammonia that depends on the particle composition (Napari et al., 2006).

For nucleation, several mechanisms can be utilized: binary $\mathrm{H}_{2} \mathrm{O}-\mathrm{H}_{2} \mathrm{SO}_{4}$ (Vehkamäki et al., 2002) and ternary $\mathrm{H}_{2} \mathrm{O}$ $\mathrm{H}_{2} \mathrm{SO}_{4}-\mathrm{NH}_{3}$ (Napari et al., 2002b) nucleation, kinetic nucleation, and activation nucleation (Kulmala et al., 2006). Here we made simulations with activation nucleation, kinetic nucleation and ternary $\mathrm{H}_{2} \mathrm{O}-\mathrm{H}_{2} \mathrm{SO}_{4}-\mathrm{NH}_{3}$ nucleation.

In activation and kinetic nucleation, the nucleation rate is directly or squarely proportional to sulphuric acid concentration:

$J_{\text {act }}=A\left[\mathrm{H}_{2} \mathrm{SO}_{4}\right]$,

$J_{\text {kin }}=K\left[\mathrm{H}_{2} \mathrm{SO}_{4}\right]^{2}$,

where $A$ and $K$ are empirical nucleation coefficients. The idea of the activation and kinetic nucleation mechanisms is based on the observed linear or square dependence between new particle formation and sulphuric acid concentration (Kulmala et al., 2006; Sihto et al., 2006). For the activation and kinetic coefficients we used the values determined for the QUEST II campaign in Hyytiälä, Finland, $A=10^{-6} \mathrm{~s}^{-1}$ and $K=5 \times 10^{-13} \mathrm{~cm}^{3} \mathrm{~s}^{-1}$ (Sihto et al., 2006). Note that the kinetic nucleation coefficient $K$ is several orders of magnitude smaller than collision rate between molecules $\left(10^{-10} \mathrm{~cm}^{3} \mathrm{~s}^{-1}\right)$, reflecting that there is some barrier involved in the nucleation process.

For the activation and kinetic nucleation mechanisms, we have to presume an initial size and composition for the nucleated particles. According to the nucleation theorem, the exponent value of the nucleation rate would be related to the number of molecules in the critical cluster. However, in activation or kinetic nucleation the exponent $n=1$ or $n=2$ could refer to the rate limiting reaction or step of the nucleation process (e.g. heterogenous nucleation), which would involve either 1 or $2 \mathrm{H}_{2} \mathrm{SO}_{4}$ molecules and a cluster with an unspecified composition. Therefore, in our simulations for activation and kinetic nucleation we assume the composition of nucleated clusters and the exponent of the nucleation rate to be uncoupled, and just assume some (arbitrary) composition for the nucleated clusters. The nucleated particles were taken to be $1 \mathrm{~nm}, 1.5 \mathrm{~nm}$ or $2 \mathrm{~nm}$ in diameter and their composition corresponded to dry ammonium bisulphate.

In case of ternary nucleation, the critical cluster size and composition come directly from the theory: $d_{\text {crit }} \approx 1-1.2 \mathrm{~nm}$ consisting of 4-6 $\mathrm{H}_{2} \mathrm{SO}_{4}, 4-6 \mathrm{NH}_{3}$ and $0-1 \mathrm{H}_{2} \mathrm{O}$-molecules, the exact numbers depending on the vapour concentrations. These molecule numbers are consistent with the nucleation theorem, e.g. $J_{\text {nuc }} \sim\left[\mathrm{H}_{2} \mathrm{SO}_{4}\right]^{4-6}$.

Particle dry deposition is calculated according to a parameterisation that is based on particle flux measurements in Hyytiälä, a boreal forest site (Rannik et al., 2003).

\subsection{Simulation parameters}

The simulation parameters were chosen to represent typical conditions of a boreal forest site in Hyytiälä, Finland. The sulphuric acid concentration had a sinusoidal profile with a maximum of $5-7 \times 10^{6} \mathrm{~cm}^{-3}$. The sulphuric acid production rate was same in all simulations, but due to different growth rates, the condensation sink differed between the simulation cases, which resulted in slightly different maximum values 
Table 1. The simulation parameters.

\begin{tabular}{llc}
\hline & Nucleation mechanism & $c_{\text {sat, org }}\left[\mathrm{cm}^{-3}\right]$ \\
\hline Case 1 & Activation & $10^{6}$ \\
Case 2 & Activation & 0 \\
Case 3 & Kinetic & $10^{6}$ \\
Case 4 & Kinetic & 0 \\
Case 5 & Ternary $\mathrm{H}_{2} \mathrm{O}-\mathrm{H}_{2} \mathrm{SO}_{4}-\mathrm{NH}_{3}$ & $10^{6}$ \\
Case 6 & Ternary $\mathrm{H}_{2} \mathrm{O}-\mathrm{H}_{2} \mathrm{SO}_{4}-\mathrm{NH}_{3}$ & 0 \\
\hline
\end{tabular}

for sulphuric acid concentration. For the condensable organic vapour we used a constant concentration of $10^{7} \mathrm{~cm}^{-3}$ in order to keep the modelling setup simple. The volatility of the organic vapor was varied by changing its saturation vapour concentration. Relative humidity and ammonia concentration were kept constant during the simulation: $\mathrm{RH}=50 \%$, $\left[\mathrm{NH}_{3}\right]=5 \mathrm{ppt}$. The simulations were performed by the fixed sections hybrid approach (for details of the method see Korhonen et al., 2004) with 50 size sections between $0.65 \mathrm{~nm}$ and $1 \mu \mathrm{m}$ (diameter).

To illustrate the connection of sulphuric acid and new particle formation, we present the results for four basic cases which describe the essential features of the system (see Table 1). In the simulations we varied the nucleation mechanism and the saturation concentration of the condensable organic vapour. In addition, the effect of the different nucleated cluster sizes $\left(d_{\text {nuc }}=1-2 \mathrm{~nm}\right)$ was investigated. Altogether, including sensitivity analyses, around 500 simulation runs were performed.

\subsection{Analysis of correlations}

Field measurements have indicated that new particle formation is related to the sulphuric acid concentration to the power from 1 to 2 (Weber et al., 1996, 1997; Sihto et al., 2006; Riipinen et al., 2007). These studies have considered the number concentration of 3-6 nm particles $\left(N_{3-6}\right)$ and the formation rate of $3 \mathrm{~nm}$ particles $\left(J_{3}\right)$, due to the fact that particle measurements start at $3 \mathrm{~nm}$. Here we consider the same quantities, in order to compare the simulation results with the measurements.

The studied correlations can be expressed mathematically in the form:

$N_{3-6}(t) \propto\left[\mathrm{H}_{2} \mathrm{SO}_{4}\right]^{n_{N_{3-6}}}\left(t-\Delta t_{N_{3-6}}\right)$

$J_{3}(t) \propto\left[\mathrm{H}_{2} \mathrm{SO}_{4}\right]^{n_{J_{3}}}\left(t-\Delta t_{J_{3}}\right)$,

where $t$ is time, $\Delta t_{N_{3-6}}$ and $\Delta t_{J_{3}}$ are the time shifts between $\mathrm{H}_{2} \mathrm{SO}_{4}$ and $N_{3-6}$ and between $\mathrm{H}_{2} \mathrm{SO}_{4}$ and $J_{3}$, respectively, and $n_{N_{3-6}}$ and $n_{J_{3}}$ are the correlation exponents. In words this means that $N_{3-6}\left(J_{3}\right)$ follows the $\mathrm{H}_{2} \mathrm{SO}_{4}$ concentration to the power of $n_{N_{3-6}}\left(n_{J_{3}}\right)$ with a time delay $\Delta t_{N_{3-6}}\left(\Delta t_{J_{3}}\right)$.
Because nucleation rate and sulphuric acid are assumed to be directly related, the time delay arises from the time required for growth from nucleation size (1-2 nm) to $3 \mathrm{~nm}$.

The correlations can be easily investigated by plotting $N_{3-6}$ or $J_{3}$ versus $\left[\mathrm{H}_{2} \mathrm{SO}_{4}\right]$ in logarithmic scale. In such scatter plots power relationships appear as straight lines with slope of the line giving the exponent of correlation:

$$
\begin{aligned}
& \ln \left(N_{3-6}\right) \propto n_{N_{3-6}} \ln \left(\left[\mathrm{H}_{2} \mathrm{SO}_{4}\right]\right)\left(t-\Delta t_{N_{3-6}}\right) \\
& \ln \left(J_{3}\right) \propto n_{J_{3}} \ln \left(\left[\mathrm{H}_{2} \mathrm{SO}_{4}\right]\right)\left(t-\Delta t_{J_{3}}\right) .
\end{aligned}
$$

From data analysis from a Finnish and a German station Riipinen et al. (2007) reported values $n_{N_{3-6}}=1-2$ and $n_{J_{3}}=1-$ 3 for the exponents and $\Delta t_{N_{3-6}}=0.8-4.5 \mathrm{~h}$ and $\Delta t_{J_{3}}=0.5-$ $4.2 \mathrm{~h}$ for the time delays. Moreover, it was observed that $n_{N_{3-6}} \leq n_{J_{3}}$ and that $n_{N_{3-6}} \leq n_{\text {nuc }}$, where $n_{\text {nuc }}$ is the exponent of nucleation. The time delays behaved as $\Delta t_{J_{3}} \leq \Delta t_{N_{3-6}}$, i.e. the rise in $N_{3-6}$ is always preceded by the rise in $J_{3}$.

The purpose of this study was to investigate how the correlation with sulphuric acid changes during the growth from nucleation size $(1-2 \mathrm{~nm})$ to sizes of 3-6 nm. If we have a linear dependence with sulphuric acid in nucleation rate $J_{\text {nuc }}$ (as according to activation nucleation, Eq. 3), what is the relationship between $J_{3}$ and $\left[\mathrm{H}_{2} \mathrm{SO}_{4}\right]$ or $N_{3-6}$ and $\left[\mathrm{H}_{2} \mathrm{SO}_{4}\right]$ ? If the relationship changes, what are the reasons for the change?

From the simulation data, $N_{3-6}$ was calculated simply as a sum of concentrations of the size bins in the range 3-6 nm. Formation rate of $3 \mathrm{~nm}$ particles $\left(J_{3}\right)$ was calculated as follows:

$$
J_{3}=\frac{N_{3}}{\Delta d_{p}} G R_{3},
$$

where $N_{3}$ is particle number concentration in a size bin of width $\Delta d_{p}$ around particle diameter $3 \mathrm{~nm}$ and $G R_{3}$ is the growth rate of $3 \mathrm{~nm}$ particles.

The particle growth rate can be calculated from the simulated volume change rate of particles:

$$
\frac{d v}{d t}=\frac{d}{d t}\left(\frac{4}{3} \pi d_{p}^{3}\right)=4 \pi d_{p}^{2} \frac{d d_{p}}{d t} .
$$

By denoting $d d_{p} / d t=G R$, we can solve the growth rate:

$$
G R\left(d_{p}\right)=\frac{d d_{p}}{d t}=\frac{1}{4 \pi d_{p}^{2}} \frac{d v\left(d_{p}\right)}{d t}
$$

The volume change rate $d v\left(d_{p}\right) / d t$ due to condensation or evaporation is obtained as output from the simulation for every size section. Using Eq. 9 we can calculate the particle growth rate as a function of particle size. 

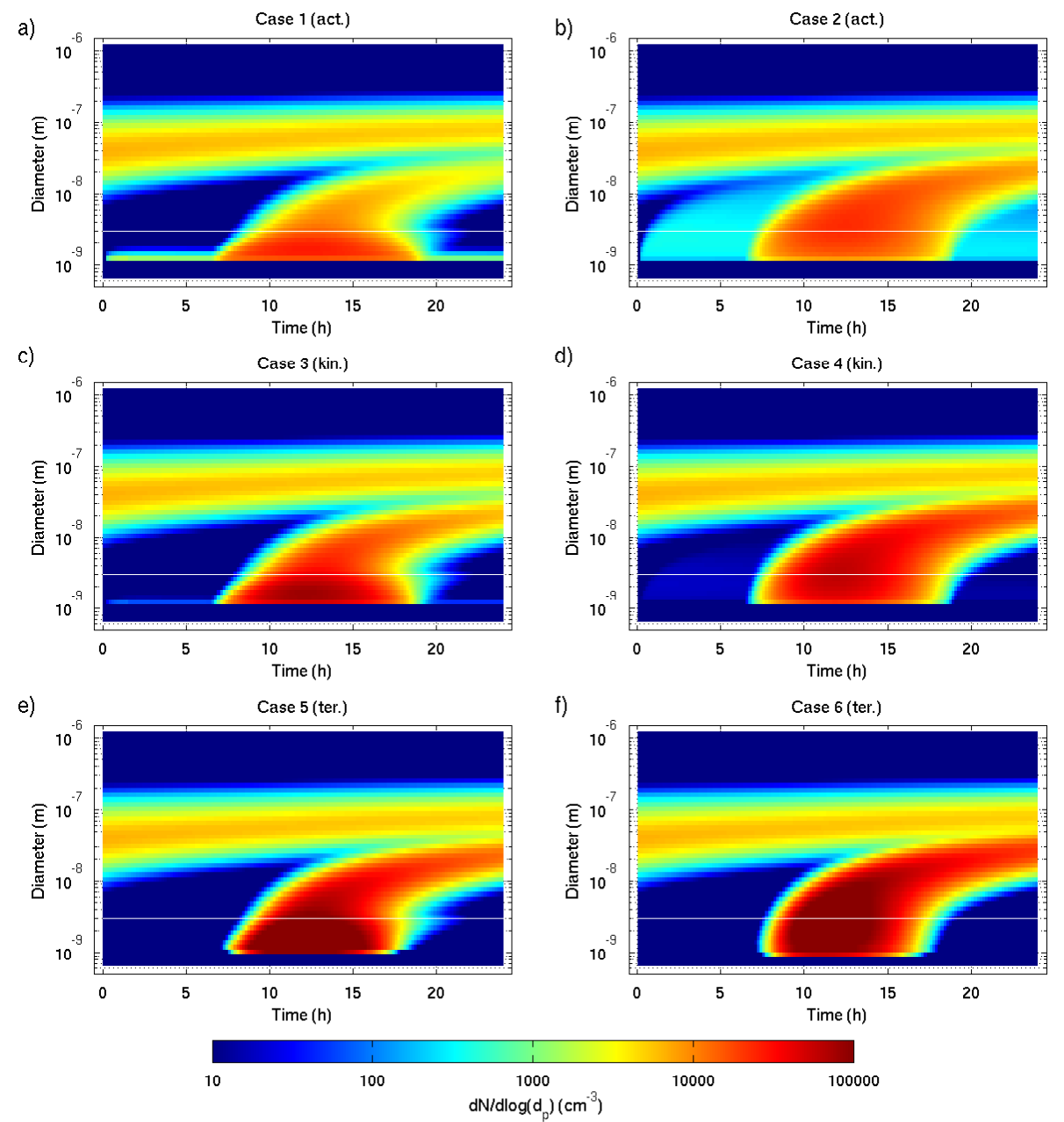

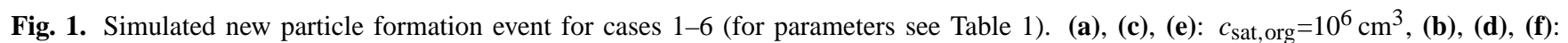
$c_{\text {sat, org }}=0 \mathrm{~cm}^{3}$. Particle diameter is on $\mathrm{y}$-axis, simulation time on $\mathrm{x}$-axis and colour indicates the normalised number concentration. White horizontal line shows the $3 \mathrm{~nm}$ border, which is the typical lower limit for particle size distribution measurements.

\section{Results and discussion}

The simulation results are presented as six cases, for which the key parameters are listed in Table 1. Case 1 is considered a base case with activation nucleation (Eq. 3) as a nucleation mechanism and organic vapour treated as semi-volatile having a saturation vapour concentration $c_{\text {sat,org }}=10^{6} \mathrm{~cm}^{-3}$.

Figure 1 shows the evolution of particle size distribution for the new particle formation events of different simulation cases. As an input, a background aerosol distribution corresponding to a typical distribution at the boreal forest site in Hyytiälä, Finland, was given. With the specified gas concentrations (see Fig. 2), evolution of aerosol size distribution was simulated according to aerosol dynamical processes, with no further constraints on background aerosol. Nucleation happens around noon, following the sulphuric acid concentration profile. Nucleated particles grow by condensation of $\mathrm{H}_{2} \mathrm{SO}_{4}$ and an organic vapour, resulting in a growing nu- cleation mode i.e. a new particle formation event. Also background particle distribution grows by condensation of $\mathrm{H}_{2} \mathrm{SO}_{4}$ and organic vapour.

From Fig. 1 some important differences between the simulation cases can be observed: With activation nucleation (cases 1 and 2) 1-2 nm sized particles are formed throughout the whole one day simulation, whereas with ternary nucleation (cases 5 and 6) particles are produced for a shorter time but with a greater intensity. This results in a more intense nucleation event with ternary nucleation. The events with kinetic nucleation (cases 3 and 4) resemble the events with activation nucleation, but with a greater intensity of particle formation due to the squared dependence on sulphuric acid. The effect of the organic vapour saturation concentration shows in the growth of freshly nucleated particles, especially below particle size of $3 \mathrm{~nm}$. With a low organic vapour saturation concentration $\left(c_{\mathrm{sat}, \text { org }}=0 \mathrm{~cm}^{-3}\right.$, cases 2,4 and 6) freshly nucleated particles grow at a significantly bigger rate than with 
a)

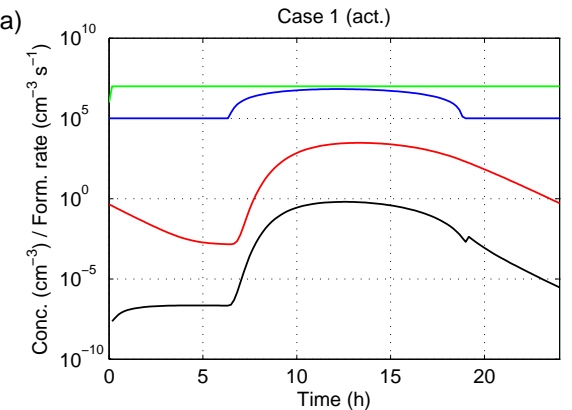

c)

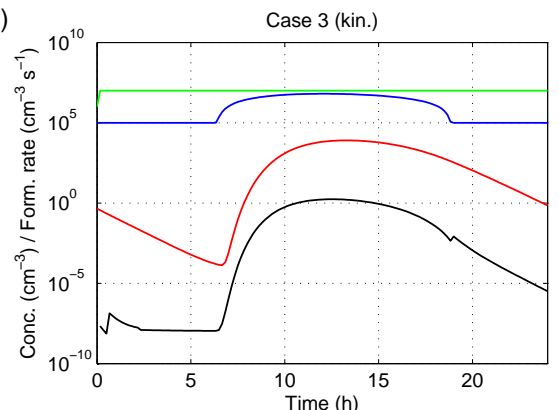

e)

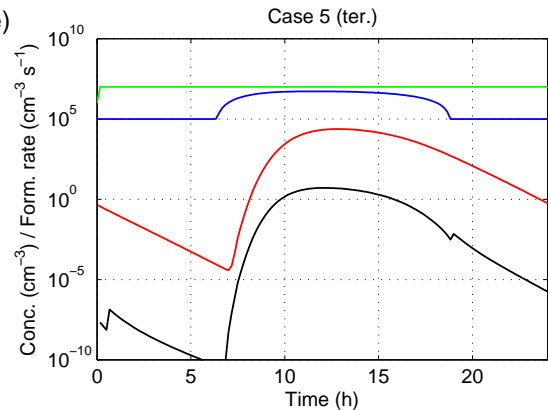

b)

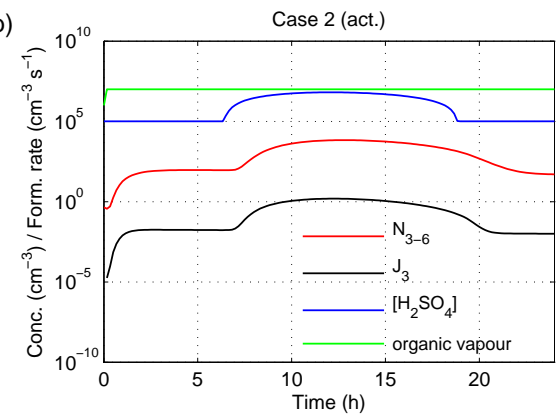

d)

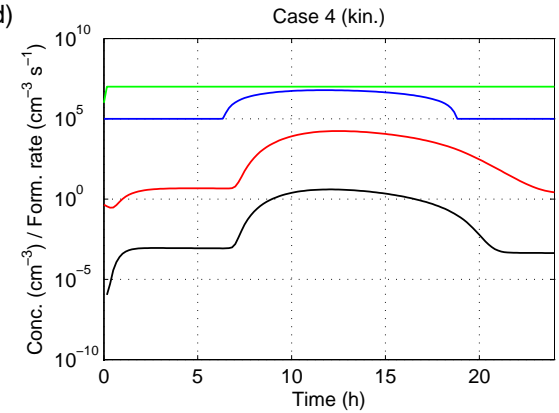

f)

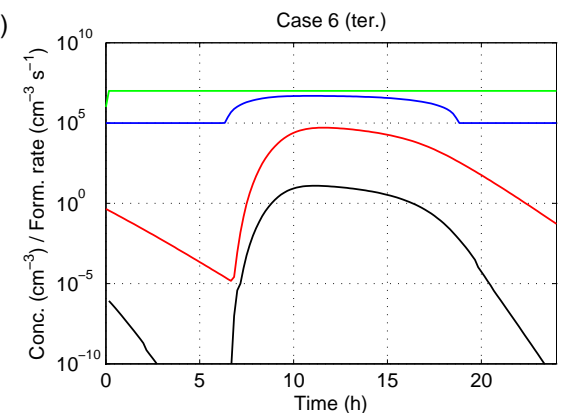

Fig. 2. Condensable gas concentrations (sulphuric acid and an organic vapour, given as input for the simulation) and simulated formation rate of $3 \mathrm{~nm}$ particles $\left(J_{3}\right)$ and number concentration of 3-6 nm particles $\left(N_{3-6}\right)$ as a function of time for simulation cases 1-6 (a-f).

a higher saturation concentration $\left(c_{\mathrm{sat}, \mathrm{org}}=10^{6} \mathrm{~cm}^{-3}\right.$, cases 1 , 3 and 5). This changes the shape of the particle formation event and makes it broader for the cases with low $c_{\text {sat,org }}$. Also, particle formation event becomes more intense, when bigger growth rate makes greater fraction of nucleated particles to survive to bigger sizes before coagulating with background particles.

In the following we investigate the correlations of formation rate of $3 \mathrm{~nm}$ particles $\left(J_{3}\right)$ and $3-6 \mathrm{~nm}$ particle number concentration $\left(N_{3-6}\right)$ with sulphuric acid. The profiles of simulated $J_{3}$ and $N_{3-6}$ as a function of time, together with the condensable gas concentrations which were given as input for the simulation, are shown in Fig. 2 for all simulation cases. First we present the model results for the case 1, and then compare it with other simulation cases.

\subsection{General correlation of $J_{\text {nuc }}, J_{3}$, and $N_{3-6}$ with sul- phuric acid concentration}

In this study we are interested in the relationship between sulphuric acid concentration and freshly nucleated particles, and specifically in how the relationship changes during particle growth from nucleation size to $3-6 \mathrm{~nm}$ size range. Figure $3 \mathrm{a}$ presents the sulphuric acid concentration and number concentration of 3-6 nm particles $\left(N_{3-6}\right)$ for the simulation case 1 . Sulphuric acid has a sinusoidal profile, and the rise in $\left[\mathrm{H}_{2} \mathrm{SO}_{4}\right]$ is followed by rise in $N_{3-6}$ after some time delay that is required for growth from $\sim 1 \mathrm{~nm}$ to $3 \mathrm{~nm}$. This time delay is a key parameter in interpreting the relationship between $\left[\mathrm{H}_{2} \mathrm{SO}_{4}\right]$ and $N_{3-6}$.

The correlation between $N_{3-6}$ and $\left[\mathrm{H}_{2} \mathrm{SO}_{4}\right]$ can be seen more clearly by plotting $N_{3-6}$ against $\left[\mathrm{H}_{2} \mathrm{SO}_{4}\right]$ (Fig. 3c). Plotted in log-log scale, the power relationships appear as straight lines with slope of the line giving the exponent of correlation. The figure shows a clear correlation between the 

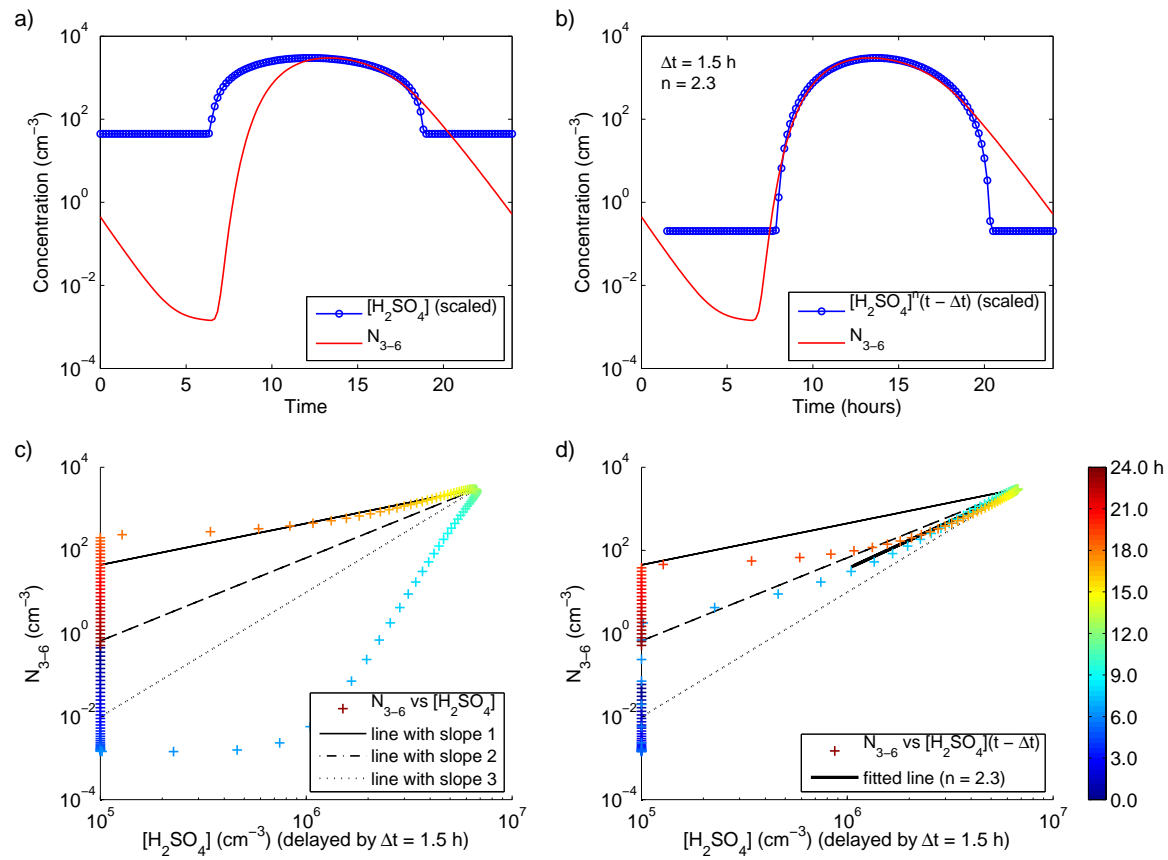

Fig. 3. The effect of time delay on the correlation between sulphuric acid concentration $\left(\left[\mathrm{H}_{2} \mathrm{SO}_{4}\right]\right)$ and number concentration of 3-6 nm particles $\left(N_{3-6}\right)$ (case 1). (a) $N_{3-6}$ and $\left[\mathrm{H}_{2} \mathrm{SO}_{4}\right]$ as a function of time during the simulation. (b) $\left[\mathrm{H}_{2} \mathrm{SO}_{4}\right]$ delayed by a time shift $\Delta t=1.5 \mathrm{~h}$ and raised to exponent $n=2.3$. (c) $N_{3-6}(t)$ versus $\left[\mathrm{H}_{2} \mathrm{SO}_{4}\right](t)$ without time shift. (d) $N_{3-6}(t)$ versus $\left[\mathrm{H}_{2} \mathrm{SO}_{4}\right](t-\Delta t)$, i.e. $\left[\mathrm{H}_{2} \mathrm{SO}_{4}\right]$ values delayed by $\Delta t=1.5 \mathrm{~h}$. The time of day $(t=0 . .24 \mathrm{~h})$ is indicated by colour code.

quantities, but with a different slope in the morning (when $\left[\mathrm{H}_{2} \mathrm{SO}_{4}\right]$ is increasing) and in the afternoon (when $\left[\mathrm{H}_{2} \mathrm{SO}_{4}\right]$ is decreasing) (see colour code for time of the day). However, by taking into account the time delay between $\left[\mathrm{H}_{2} \mathrm{SO}_{4}\right]$ and $N_{3-6}$, the correlation stays the same for most of the event time. This is demonstrated in Fig. 3d where delaying $\left[\mathrm{H}_{2} \mathrm{SO}_{4}\right]$ curve by $\Delta t_{N_{3-6}}=1.5 \mathrm{~h}$ makes the two branches of the scatter plot to almost coincide on top of each other. Fitting a line to the logarithmic data gives the correlation exponent $n_{N_{3-6}} \approx 2.3$ (see Eq. 6). The relationship between $N_{3-6}$ and $\left[\mathrm{H}_{2} \mathrm{SO}_{4}\right]$ is also shown in Fig. $3 \mathrm{~b}$ where $\left[\mathrm{H}_{2} \mathrm{SO}_{4}\right]$ values have been delayed by $\Delta t_{N_{3-6}}=1.5 \mathrm{~h}$ and raised to the exponent $n_{N_{3-6}}=2.3$.

In this study, we determined the time delay visually by searching for the value that gives the best looking correlation between $N_{3-6}$ and $\left[\mathrm{H}_{2} \mathrm{SO}_{4}\right]$, i.e. the time delay which made the points to lie on a same line in the scatter plot (see Fig. 3). Previously Sihto et al. (2006) and Riipinen et al. (2007) determined correlation exponents and time delays by finding a combination that gave the maximum correlation coefficient between $J_{3}$ or $N_{3-6}$ and $\left[\mathrm{H}_{2} \mathrm{SO}_{4}\right]^{n}$. This method worked well with measured data, but not with the simulated data used here: the simulated $J_{3}, N_{3-6}$ and $\left[\mathrm{H}_{2} \mathrm{SO}_{4}\right]$ were so smooth, that correlation coefficient was close to unity with any choice of exponent and time delay, and therefore the method could not distinguish the best correlation exponent and time delay. Nevertheless, with scatter plots the correlation between $J_{3}$ or
$N_{3-6}$ and $\left[\mathrm{H}_{2} \mathrm{SO}_{4}\right]$ could be investigated easily, and time delays and correlation exponents were straightforward to determine by visual perception. The accuracy of the time delays determined by this method is about $\pm 0.1 \mathrm{~h}$.

The scatter plots of Fig. 3 show that the time delay between $\left[\mathrm{H}_{2} \mathrm{SO}_{4}\right]$ and $N_{3-6}$ is of crucial importance when studying the correlation between these quantities. Using improper time delay can lead to misleading or false conclusions. For example, the correlation exponents determined from the data without any time shift (Fig. 3c), would be $n \approx 7.3$ for the rising part and $n \approx 1.2$ for the decreasing part of the curve.

One may question which way of looking at the data is correct: with or without the time shift. We claim that the time delay has to be taken into account. There are several reasons for this: First, with the time delay, there is the same correlation (with the same exponent) between $N_{3-6}$ and $\left[\mathrm{H}_{2} \mathrm{SO}_{4}\right]$ during most of the event time (see Fig. 3d). This gives confidence that the correlation is not an artefact. Second, the time delay between $N_{3-6}$ and $\left[\mathrm{H}_{2} \mathrm{SO}_{4}\right]$ means that it is the nucleation rate that depends on $\left[\mathrm{H}_{2} \mathrm{SO}_{4}\right]$, and not $J_{3}$ or $N_{3-6}$. This is what is expected, and the time delay arises due to the finite growth time from the nucleation size to $3 \mathrm{~nm}$.

It is somewhat surprising that a constant time delay works fairly well for the whole new particle formation event, even though the particle growth rate is not constant, but changes both as a function of time and particle size (see Sect. 3.2 for more discussion). 

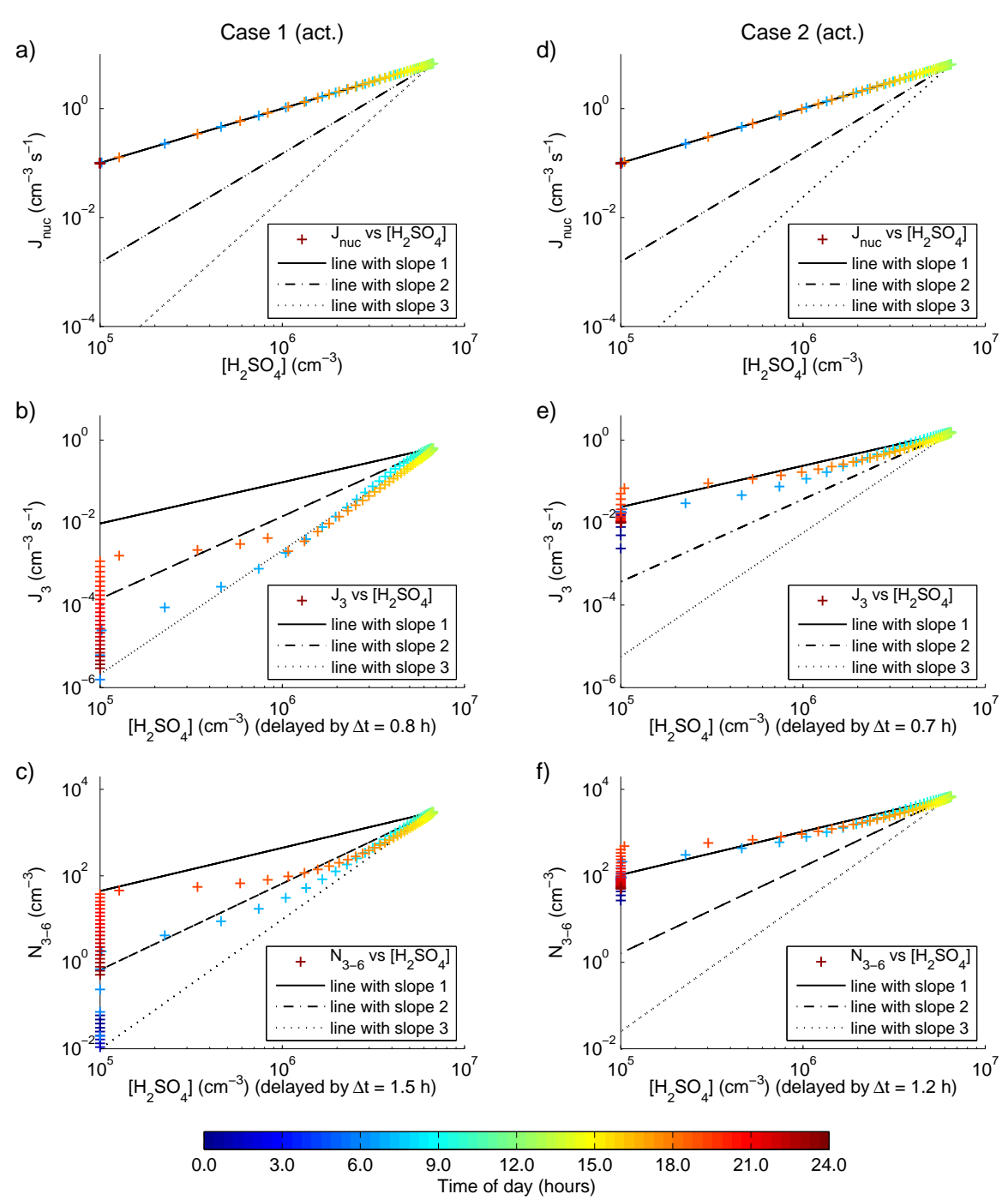

Fig. 4. Correlation of nucleation rate $\left(J_{\text {nuc }}\right.$, top), $3 \mathrm{~nm}$ particle formation rate $\left(J_{3}\right.$, middle) and 3-6 nm particle number concentration $\left(N_{3}-6\right.$, bottom) with $\left[\mathrm{H}_{2} \mathrm{SO}_{4}\right]$ for simulation cases $1(\mathbf{a}, \mathbf{b}, \mathbf{c})$ and $2(\mathbf{d}, \mathbf{e}, \mathbf{f})$ with activation as nucleation mechanism $\left(d_{\mathrm{nuc}}=1 \mathrm{~nm}\right)$. For $J_{3}$ and $N_{3}-6$ scatter plots $\left[\mathrm{H}_{2} \mathrm{SO}_{4}\right]$ has been delayed by the time shift $\Delta t$ determined visually from the data to give the best correlation. Straight lines with slopes 1, 2 and 3 correspond the exponential dependences $\sim\left[\mathrm{H}_{2} \mathrm{SO}_{4}\right], \sim\left[\mathrm{H}_{2} \mathrm{SO}_{4}\right]^{2}, \sim\left[\mathrm{H}_{2} \mathrm{SO}_{4}\right]^{3}$. The time of day $(t=0 \ldots 24 \mathrm{~h})$ is indicated by colour code.

\subsection{Effect of size-dependent particle growth rate: or- ganic vapour and sulphuric acid}

We now present the correlations of simulated $J_{3}$ and $N_{3-6}$ with $\left[\mathrm{H}_{2} \mathrm{SO}_{4}\right]$ using scatter plots, where the time delay between $\left[\mathrm{H}_{2} \mathrm{SO}_{4}\right]$ and $J_{3}$ or $N_{3-6}$ was determined visually (as described above for $N_{3-6}$; see Fig. 3). For simulation case 1, the correlation exponent with $\left[\mathrm{H}_{2} \mathrm{SO}_{4}\right]$ was significantly different for nucleation rate at $\sim 1 \mathrm{~nm}\left(J_{\text {nuc }}\right)$ and for formation rate at $3 \mathrm{~nm}\left(J_{3}\right)$ (Fig. 4a and b). In addition, the correlation exponent for $N_{3-6}$ was different than for the formation rates (Fig. 4c). With activation as nucleation mechanism, the correlation exponent for $J_{\text {nuc }}$ is $n_{\text {nuc }}=1$, but for $J_{3}$ the exponent changed to $n_{J_{3}} \approx 3.2$ (exponent fitted to the logarithmic data). For $N_{3-6}$ the exponent was slightly smaller than for $J_{3}, n_{N_{3-6}} \approx 2.3$. In the scatter plots the time of day is indicated by colour, showing that correlation changes somewhat, especially for $N_{3-6}$, during the course of the one-day simulation.

The steeper dependence on sulphuric acid for $J_{3}$ than for $N_{3-6}\left(n_{J_{3}} \geq n_{N_{3-6}}\right)$ is consistent with the measurement data analysis (Riipinen et al., 2007). In addition, $J_{3}$ starts to increase before $N_{3-6}$ : the time delay between $\left[\mathrm{H}_{2} \mathrm{SO}_{4}\right]$ and $J_{3}$ is $\Delta t_{J_{3}}=0.8 \mathrm{~h}$, but between $\left[\mathrm{H}_{2} \mathrm{SO}_{4}\right]$ and $N_{3-6}$ the time delay is $\Delta t_{N_{3-6}}=1.5 \mathrm{~h}$. These are explained by number concentration being an integral quantity of the formation rate.

In field measurement data from e.g. boreal forest, $J_{3}$ and $N_{3-6}$ are observed to correlate with sulphuric acid 


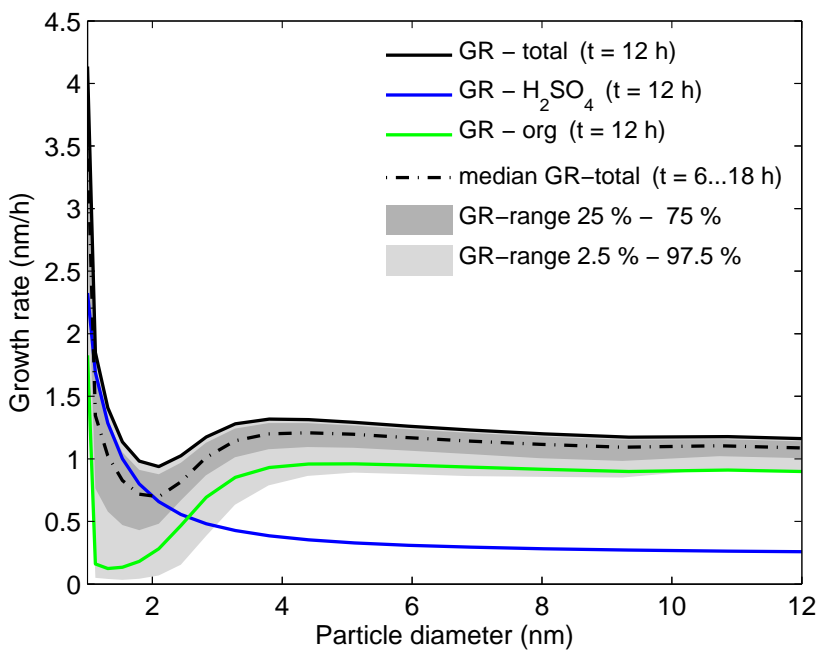

Fig. 5. Particle growth rate dependence on particle size for simulation case 1 (with $c_{\mathrm{sat} \text {, org }}=10^{6} \mathrm{~cm}^{-3}$ ). Solid lines give the instantaneous growth rates at noon $(t=12 \mathrm{~h})$ : total growth rate $\left(\mathrm{H}_{2} \mathrm{SO}_{4}+\right.$ organic, black line), and the contributions of sulphuric acid (blue) and organic vapour (green) separated. Dash-dotted line gives the median of total growth rate and grey areas indicate the 25 and 2.5 percentiles, showing the total growth rate variability during the event time (from 06:00 a.m. to 06:00 p.m., $t=6 \ldots 18 \mathrm{~h}$ ).

concentration to the power of 1-2 (Riipinen et al., 2007). Thus the results of simulation case 1, with correlation exponents close to 3 , seem not to correspond the observations very well. Therefore we tried to find parameters that would yield lower correlation exponents for $J_{3}$ and $N_{3-6}$.

The relationship of $J_{3}$ and $N_{3-6}$ with sulphuric acid was greatly affected by the growth rate between 1 and $3 \mathrm{~nm}$. In case 1 , the growth between 1 and $3 \mathrm{~nm}$ was mainly by sulphuric acid, but after $2 \mathrm{~nm}$ the organic vapour started to condense gradually according to the nano-Köhler mechanism. The growth rate profile between 1 and $12 \mathrm{~nm}$, calculated with Eq. 9, and the contributions of sulphuric acid and organic vapour are presented in Fig. 5. Below $\sim 4 \mathrm{~nm}$, the growth rate due to sulphuric acid increases with decreasing particle size. This results from the molecular enhancement in the condensation flux (Lehtinen and Kulmala, 2003). Combined with the growth rate due to nano-Köhler organics, which increases with particle size at size range $1-4 \mathrm{~nm}$, we get the total growth rate that has a minimum around $d_{p}=2 \mathrm{~nm}$. Besides the size dependence, the growth rate varies also as a function of time, according to the gas concentrations (variability indicated by grey areas in Fig. 5). Since organic vapour concentration is kept constant, only the sulphuric acid part of the growth rate changes during the simulation.

The minimum in growth rate causes a bottleneck effect that retards the increase of $J_{3}$ and $N_{3-6}$ compared to nucleation rate $J_{\text {nuc }}$. This may be the reason why in case 1 the relationship with sulphuric acid for $J_{3}$ and $N_{3-6}$ differs clearly from that for $J_{\text {nuc }}$.

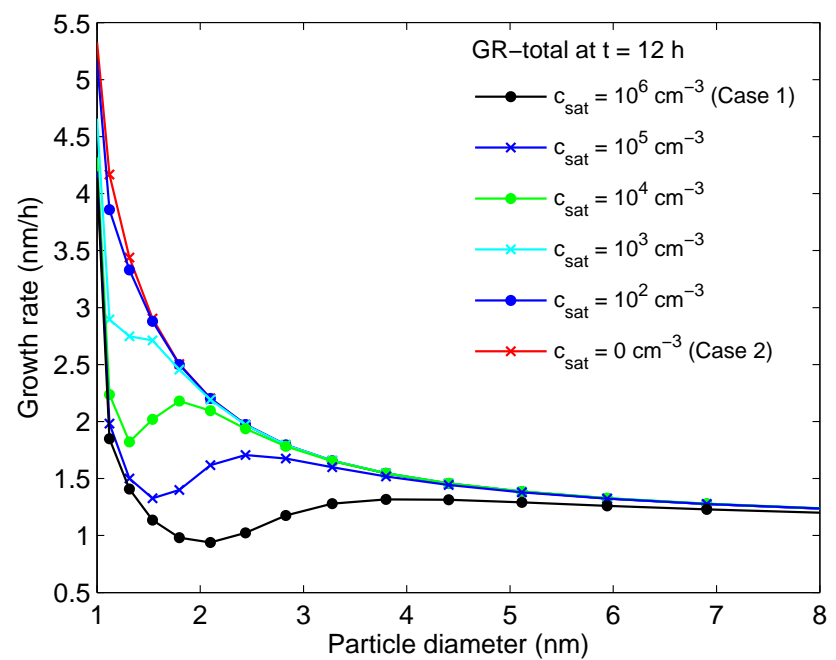

Fig. 6. Total particle growth rate as a function of particle size for different saturation concentration $\left(c_{\mathrm{sat}, \mathrm{org}}\right)$ values of the organic vapour (see legend). Each curve presents the total growth rate due to both $\mathrm{H}_{2} \mathrm{SO}_{4}$ and organic vapour condensation at one time moment of the simulation ( $t=12 \mathrm{~h}$, when the growth rate is at maximum). For the actual concentrations of $\mathrm{H}_{2} \mathrm{SO}_{4}$ and organic vapour see Fig. 2.

\subsubsection{Effect of the organic vapour saturation concentra- tion}

We made a set of simulations, in which the saturation concentration of organic vapour $\left(c_{\mathrm{sat}, \text { org }}\right)$ was lowered from $10^{6} \mathrm{~cm}^{-3}$ (case 1) to $0 \mathrm{~cm}^{-3}$ (case 2) in steps of a factor of 10. Decreasing $c_{\text {sat,org }}$ makes the condensation of organic vapour less limited by the Kelvin effect, and decreases the diameter when organic vapour starts to condense on particles. Together with the growth rate due to sulphuric acid, this makes the minimum in total growth rate to shift to smaller particle size (see Fig. 6). When $c_{\text {sat,org }}$ approaches $0 \mathrm{~cm}^{-3}$, organic vapour condenses as sulphuric acid, with a similar profile as a function of particle size.

Decreasing the saturation concentration of the condensable organic vapour lowered the correlation exponents for $J_{3}$ and $N_{3-6}$. With $c_{\text {sat,org }}=0 \mathrm{~cm}^{-3}$ the correlation of $J_{3}$ and $N_{3-6}$ with sulphuric acid was close to linear, the fitted exponents being $n_{J_{3}} \approx 1.3$ and $n_{N_{3-6}} \approx 1.2$. This is reflected by the scatter plots of Fig. 4 (case 2; d, e, f). In between these two cases (case 1 and 2), the correlation exponents for $J_{3}$ and $N_{3-6}$ decreased gradually from $n \sim 2-3$ to $n \sim 1$, as $c_{\text {sat,org }}$ changed from $10^{6}$ to $0 \mathrm{~cm}^{-3}$.

Setting $c_{\mathrm{sat}, \text { org }}=0 \mathrm{~cm}^{-3}$ for the organic vapour means that it condenses with a maximum flux and with no Kelvin effect, similarly as sulphuric acid. For sulphuric acid this assumption is reasonable, but organic substances, which are typically rather big molecules, are unlikely to be totally nonvolatile. One possibility could be that some oligomerisation reactions, taking place on particle surfaces, would convert 
semi-volatile organic vapours into particulate compounds of very low volatility (e.g. Zhang et al, 2002; Limbeck et al., 2003; Wehner et al., 2007; Heaton et al., 2007). The same growth rate profile as with $c_{\mathrm{sat}, \mathrm{org}}=0 \mathrm{~cm}^{-3}$ could be achieved also when sulphuric acid accounts for the whole growth below $\sim 4 \mathrm{~nm}$. However, for the conditions of Hyytiälä boreal forest site, the sulphuric acid concentration can explain only part of the observed growth rate: Boy et al. (2005) have estimated the sulphuric acid contribution to be $4-31 \%$. In our simulations, the sulphuric acid made $20-25 \%$ of the total growth rate (above $\sim 4 \mathrm{~nm}$ ), which corresponds well to a typical situation in Hyytiälä.

\subsubsection{Sensitivity studies on the effect of particle growth rate}

Above we investigated the effect of organic vapour saturation concentration on the correlation exponents. Other factors that could affect the correlations are the concentrations of condensable vapours (both sulphuric acid and organic) and the coagulational sink. If these quantities change during the simulation, they can shape the $J_{3}$ and $N_{3-6}$ profiles: varying vapour concentration causes varying particle growth rate, and varying coagulation sink causes varying removal rate for small particles. For example, if the organic vapour would have a sinusoidal profile, this would yield a bigger correlation exponent for $J_{3}$ and $N_{3-6}$ than in the case where organic vapour concentration is constant.

We made sensitivity tests for the correlations by varying both the profile (i.e. time evolution) of the organic vapour and its concentration (i.e. the magnitude of the growth rate). Tested organic vapour profiles were: a constant production rate and an $\mathrm{OH}-$ dependent production rate (sinusoidal profile). Introducing an $\mathrm{OH}$-dependent profile for the condensable organic vapour increased the correlation exponents for $J_{3}$ and $N_{3-6}$. The higher was the $\mathrm{OH}$-dependent production term, the higher were the correlation exponents. Also increasing the concentration of sulphuric acid, so that bigger part of the growth was made by it, increased the correlation exponents. There seems to be two qualitative features influencing the correlations: i) the size dependence of $G R$ (through $c_{\text {sat,org }}$ ) and ii) the time dependence of $G R$ (through the profile of condensable vapours). Both a strong size dependence in $G R$ with a minimum around $d_{p}=2 \mathrm{~nm}$ (see Fig. 5) and a sinusoidal time dependence for $G R$ increased the correlation exponents for $J_{3}$ and $N_{3-6}$.

Regarding the field observations that show that particle formation rate at $3 \mathrm{~nm}$ is related to sulphuric acid to the power 1-2, the simulation of case 2 appears to give a closer agreement with field measurements than case 1 . According to the sensitivity tests, in order to preserve the exponent $n_{\text {nuc }}=1$ of the nucleation rate, we need to have a rather high concentration of organic vapour (i.e. big part of the $G R$ made by organic vapour), with a fairly constant profile dur- ing the event and a small saturation vapour pressure. This corresponds to the parameter set of case 2 .

Here the saturation vapour concentration of organic vapour (or some other property of the vapour that lowers the equilibrium pressure, see Eqs. 1 and 2) was a key parameter: without decreasing $c_{\text {sat,org }}$ we were not able to reproduce exponents close to $n_{N_{3-6}} \approx 1$. Increasing the organic vapour concentration, so that the difference $\left(p_{\text {org }}-p_{\text {eq,org }}\right)$ would be significantly bigger for smallest particles, does not solve the problem: if $c_{\mathrm{sat}, \text { org }} \gg 0$, the growth of smallest particles would still be inhibited by the Kelvin effect, due to exponential dependence of $p_{\text {eq,org }}$ on the particle size (see Eqs. 1 and 2). Also, increasing the organic vapour concentration increases condensation on bigger particles, and therefore the concentrations cannot be increased very much to avoid unrealistically high growth rates for the background aerosol. Thus, the size dependence of the growth rate, which is affected by $c_{\text {sat,org }}$, appears to be the key factor. To be able to reproduce exponent values close to $n \approx 1$ for $J_{3}$ and $N_{3-6}$, it

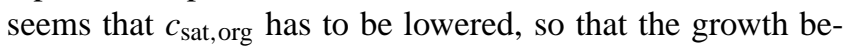
low $3 \mathrm{~nm}$ is fast and the retarding effect of the growth rate bottleneck (see Fig. 6) is diminished.

\subsection{Effect of the nucleated cluster size}

Recently Kulmala et al. (2007) have reported experimental evidence that processes initiating atmospheric particle formation happen at particle sizes $1.5-2 \mathrm{~nm}$. In the simulations presented above, activation nucleation was assumed to produce clusters of $\sim 1 \mathrm{~nm}$ diameter, which has previously been thought to be the critical cluster size in atmospheric nucleation. To be concordant with recent findings, we made also simulations with nucleated cluster size of 1.5 and $2 \mathrm{~nm}$.

The correlations of $J_{3}$ and $N_{3-6}$ with sulphuric acid concentration were analysed similarly as above by making scatter plots. Time delays to sulphuric acid were determined visually by finding a value that yielded the best correlation, after which a straight line was fitted to the logarithmic data. The slope of the fitted line gives the exponent of the correlation between $J_{3}$ or $N_{3-6}$ and sulphuric acid.

The results for the simulation cases 1 and 2, with nucleated cluster sizes $1 \mathrm{~nm}, 1.5 \mathrm{~nm}$ and $2 \mathrm{~nm}$, are presented in Table 2. As the nucleation size gets bigger, it is obvious that the time shift between $\left[\mathrm{H}_{2} \mathrm{SO}_{4}\right]$ and $J_{3}$ or $N_{3-6}$ gets smaller. Also correlation exponents decrease, as aerosol dynamical processes have less time to change the relationship with sulphuric acid from that in the nucleation rate. Most importantly, with $d_{\text {nuc }}=2 \mathrm{~nm}$, the correlation of $N_{3-6}$ with sulphuric acid is close to linear for both cases (case 1: $n_{N_{3-6}}=1.2$, case $2: n_{N_{3-6}}=1.0$ ), despite the different saturation concentration for the condensable organic vapour. From Table 2 it can also be seen that $\Delta t_{J_{3}}<\Delta t_{N_{3-6}}$ and $n_{J_{3}}>n_{N_{3-6}}$, which is consistent with the analysis of measurement data (Riipinen et al., 2007) and expected as $N_{3-6}$ is an integrated quantity of $J_{3}$. 
Table 2. Effect of nucleated cluster size in activation nucleation mechanism on the correlation exponents and the time delays at $3 \mathrm{~nm}\left(n_{J_{3}}\right.$ and $\Delta t_{J_{3}}$ : exponent and time delay for correlation of $J_{3}$ and $\left[\mathrm{H}_{2} \mathrm{SO}_{4}\right] ; n_{N_{3-6}}$ and $\Delta t_{N_{3-6}}$ : exponent and time delay for correlation of $N_{3-6}$ and $\left.\left[\mathrm{H}_{2} \mathrm{SO}_{4}\right]\right)$.

\begin{tabular}{llll}
\hline & $d_{\text {nuc }}=1.0 \mathrm{~nm}$ & $d_{\text {nuc }}=1.5 \mathrm{~nm}$ & $d_{\text {nuc }}=2.0 \mathrm{~nm}$ \\
\hline Case 1 & $n_{J_{3}}=3.2$ & $n_{J_{3}}=2.2$ & $n_{J_{3}}=1.4$ \\
[activation, & $n_{N_{3-6}}=2.3$ & $n_{N_{3-6}}=1.7$ & $n_{N_{3-6}}=1.2$ \\
$c_{\text {sat,org }}=10^{6} \mathrm{~cm}^{-3}$ ] & $\Delta t_{J_{3}}=0.8 \mathrm{~h}$ & $\Delta t_{J_{3}}=0.5 \mathrm{~h}$ & $\Delta t_{J_{3}}=0.4 \mathrm{~h}$ \\
& $\Delta t_{N_{3-6}}=1.5 \mathrm{~h}$ & $\Delta t_{N_{3-6}}=1.2 \mathrm{~h}$ & $\Delta t_{N_{3-6}}=1.0 \mathrm{~h}$ \\
\hline Case 2 & $n_{J_{3}}=1.3$ & $n_{J_{3}}=1.3$ & $n_{J_{3}}=1.1$ \\
[activation, & $n_{N_{3-6}}=1.2$ & $n_{N_{3-6}}=1.1$ & $n_{N_{3-6}}=1.0$ \\
$c_{\text {sat,org }}=0 \mathrm{~cm}^{-3}$ ] & $\Delta t_{J_{3}}=0.7 \mathrm{~h}$ & $\Delta t_{J_{3}}=0.5 \mathrm{~h}$ & $\Delta t_{J_{3}}=0.3 \mathrm{~h}$ \\
& $\Delta t_{N_{3-6}}=1.2 \mathrm{~h}$ & $\Delta t_{N_{3-6}}=1.1 \mathrm{~h}$ & $\Delta t_{N_{3-6}}=0.8 \mathrm{~h}$ \\
\hline
\end{tabular}

Table 3. Effect of the nucleation mechanism on the correlation exponents $n_{J_{3}}$ and $n_{N_{3-6}}$. The nucleated cluster size was $d_{\text {nuc }}=1 \mathrm{~nm}$.

\begin{tabular}{llll}
\hline & $\begin{array}{l}\text { Activation nucleation } \\
n_{\text {nuc }}=1\end{array}$ & $\begin{array}{l}\text { Kinetic nucleation } \\
n_{\text {nuc }}=2\end{array}$ & $\begin{array}{l}\text { Ternary nucleation } \\
n_{\text {nuc }} \approx 5.6\end{array}$ \\
\hline$c_{\text {sat, org }}=10^{6} \mathrm{~cm}^{-3}$ & $n_{J_{3}}=3.2$ & $n_{J_{3}}=3.4$ & $n_{J_{3}}=5.6$ \\
& $n_{N_{3-6}}=2.3$ & $n_{N_{3-6}}=2.3$ & $n_{N_{3-6}}=4.1$ \\
\hline$c_{\text {sat, org }}=0 \mathrm{~cm}^{-3}$ & $n_{J_{3}}=1.3$ & $n_{J_{3}}=2.1$ & $n_{J_{3}}=5.0$ \\
& $n_{N_{3-6}}=1.2$ & $n_{N_{3-6}}=1.7$ & $n_{N_{3-6}}=4.0$ \\
\hline
\end{tabular}

Thus increasing the nucleated cluster size from $1 \mathrm{~nm}$ to 1.5-2 nm makes the correlation exponents to stay closer to the nucleation exponent, $n_{\text {nuc }}=1$ (in case of activation nucleation). With $d_{\text {nuc }}=1.5-2 \mathrm{~nm}$ we need not to reduce the saturation concentration of the condensable organic vapour $\left(c_{\text {sat,org }}\right)$ greatly in order to achieve linear, or close to linear, correlation for $J_{3}$ and $N_{3-6}$ with sulphuric acid. Already with $c_{\text {sat,org }}=10^{5} \mathrm{~cm}^{-3}$ the correlation exponents for $J_{3}$ and $N_{3-6}$ are in range $1-1.5$. This is a promising result, since realistic values for saturation concentrations of condensable organic vapours are probably of the order $10^{5}-10^{6} \mathrm{~cm}^{-3}$ (see e.g. Kulmala et al., 1998).

\subsection{Comparison of different nucleation mechanisms}

As there is no definite certainty on the actual nucleation mechanism taking place in the atmosphere, we performed additional simulations with kinetic and ternary $\mathrm{H}_{2} \mathrm{O}-\mathrm{H}_{2} \mathrm{SO}_{4}$ $\mathrm{NH}_{3}$ nucleation mechanisms (cases 3-6, for the parameters see Table 1). For an overall comparison between different nucleation mechanisms, see particle formation events and $J_{3}$, $N_{3-6}$ and condensable gas concentrations in Figs. 1 and 2 , respectively.

The correlation exponents for $J_{\text {nuc }}, J_{3}$ and $N_{3-6}$ with $\left[\mathrm{H}_{2} \mathrm{SO}_{4}\right]$ for different nucleation mechanisms are compared in Table 3. The exponents were determined similarly as described above for the activation nucleation case (Sect. 3.1.).
Exponents for the ternary nucleation are significantly bigger than for activation and kinetic nucleation. Interestingly, exponents $n_{J_{3}}$ and $n_{N_{3-6}}$ for kinetic and activation nucleation are similar, when $c_{\text {sat,org }}=10^{6} \mathrm{~cm}^{-3}$ : the size dependent growth rate appears to mask the information on the nucleation exponent during growth from $\sim 1 \mathrm{~nm}$ to $3 \mathrm{~nm}$. With $c_{\text {sat, org }}=0 \mathrm{~cm}^{-3}$ the difference between kinetic and activation nucleation exponents is $\approx 0.5-0.8$.

Figure 7 presents the relationships of $J_{\text {nuc }}, J_{3}$ and $N_{3-6}$ with sulphuric acid for the ternary cases. The ternary nucleation rate has a steep dependence on $\left[\mathrm{H}_{2} \mathrm{SO}_{4}\right]$ : the slope of the $\log \left(J_{\text {nuc }}\right)$ vs. $\log \left(\mathrm{H}_{2} \mathrm{SO}_{4}\right)$ data is 5.6. This means that on average there are $5-6 \mathrm{H}_{2} \mathrm{SO}_{4}$ molecules in the critical cluster, although the number changes slightly during the simulation according to the sulphuric acid concentration. The diameter of the critical cluster, i.e. the nucleated cluster size, is $\sim 1 \mathrm{~nm}$, as is seen from Fig. 1e and f. In ternary nucleation the critical cluster size is calculated according to theory (Napari et al., 2002b), and therefore sensitivity tests with respect to cluster size are not relevant.

Also with ternary nucleation the growth from nucleation size $\sim 1 \mathrm{~nm}$ to $3 \mathrm{~nm}$ changes the relationship with sulphuric acid (see Fig. 7 or Table 3). However, with ternary nucleation, the relationship of $J_{3}$ and $N_{3-6}$ with sulphuric acid seems to vary more during the simulation: there is a bigger difference between the rising and decreasing parts of the $J_{3}$ and $N_{3-6}$ curves than with activation nucleation (see colour 

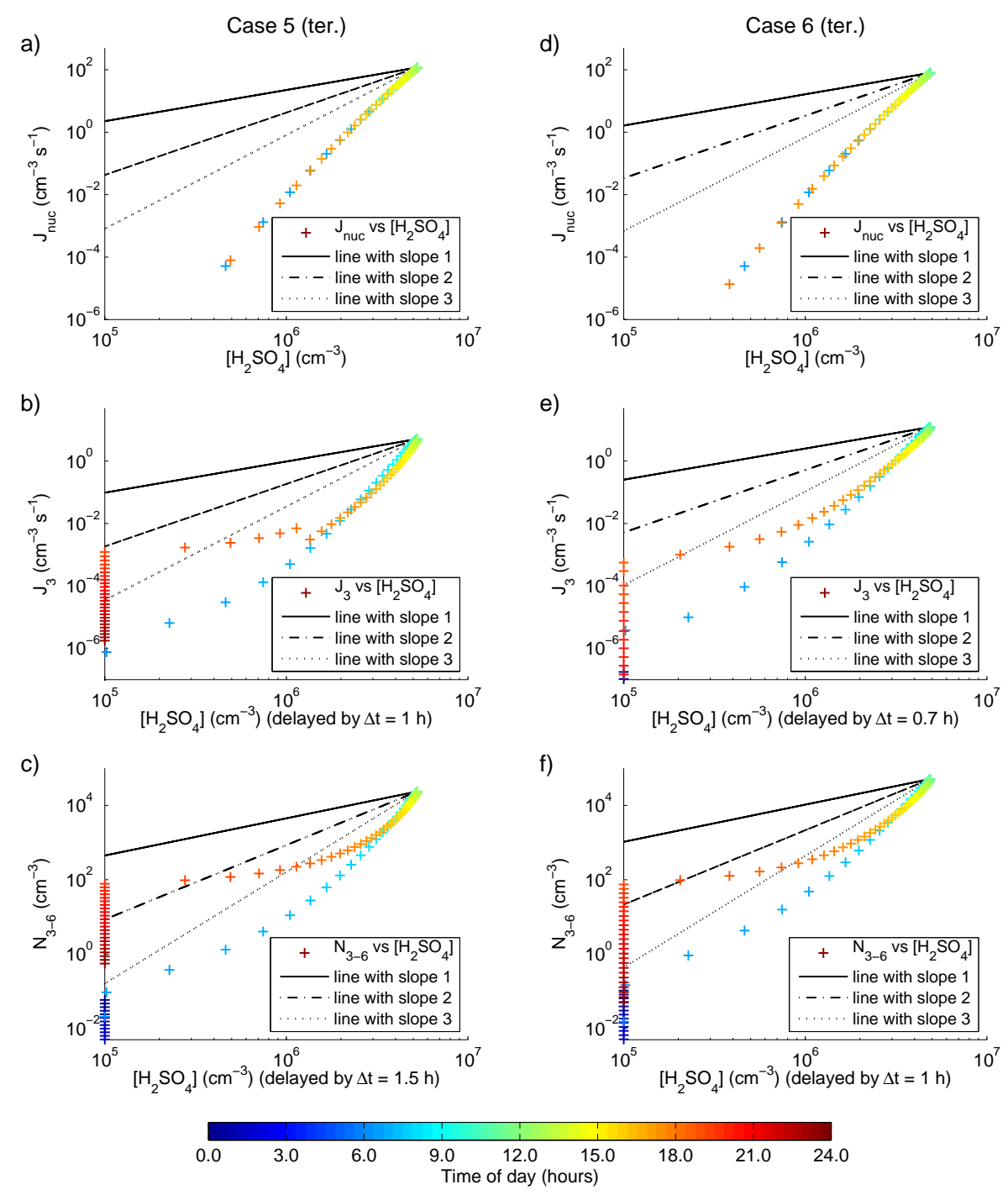

Fig. 7. Correlation of nucleation rate ( $J_{\text {nuc }}$, top), $3 \mathrm{~nm}$ particle formation rate $\left(J_{3}\right.$, middle) and $3-6 \mathrm{~nm}$ particle number concentration $\left(N_{3}-6\right.$, bottom) with $\left[\mathrm{H}_{2} \mathrm{SO}_{4}\right]$ for simulation cases $3(\mathbf{a}, \mathbf{b}, \mathbf{c})$ and $4(\mathbf{d}, \mathbf{e}, \mathbf{f})$ with ternary nucleation. See Fig. 4 for more explanations.

code in Figs. 4 and 7). When going from $J_{\text {nuc }}$ to $J_{3}$ and $N_{3-6}$, the correlation exponent decreases, as opposed to increasing exponent in cases with activation nucleation (see Table 3). Also, contrary to activation and kinetic nucleation cases, there is no big difference in the relationship with sulphuric acid between the two ternary cases with different saturation concentration of the organic vapour. Thus it seems that in ternary cases the growth rate in $1-3 \mathrm{~nm}$ size range does not have such a crucial impact on the relationship between $J_{3}$ or $N_{3-6}$ and sulphuric acid as in cases with activation nucleation. These differences between activation and ternary cases may be related to the high nucleation rates that ternary nucleation reproduces, resulting in high coagulation rates for the smallest particles, which affects the shape of the $J_{3}$ and $N_{3-6}$ curves differently than the size-dependent growth rate.
Overall, with ternary nucleation, the correlation exponents for the relationships $J_{3} \sim\left[\mathrm{H}_{2} \mathrm{SO}_{4}\right]^{n}$ and $N_{3-6} \sim\left[\mathrm{H}_{2} \mathrm{SO}_{4}\right]^{n}$ were significantly bigger than with activation or kinetic mechanism. Exponents clearly exceeded unity $(n \gg 1)$, and by altering any simulation parameters in reasonable ranges we were not able to reproduce correlation exponents even close to $n=2$. This suggests that ternary $\mathrm{H}_{2} \mathrm{O}-\mathrm{H}_{2} \mathrm{SO}_{4}-\mathrm{NH}_{3}$ nucleation cannot explain particle formation in atmospheric boundary layer, where observations have shown particle formation to correlate with sulphuric acid concentration to the power $n=1-2$. 


\section{Conclusions}

The simulation results showed that the correlation with sulphuric acid can be significantly different for particle formation rate at $3 \mathrm{~nm}\left(J_{3}\right)$ and number concentration at $3-6 \mathrm{~nm}$ $\left(N_{3-6}\right)$ than for nucleation rate. With activation nucleation mechanism and nucleated cluster size of $1 \mathrm{~nm}$, the growth process could change the exponent from $n=1$ at the nucleation rate to $n=2.3$ for $N_{3-6}$ and $n=3.2$ for $J_{3}$. This means, that the correlation exponents observed for $J_{3}$ or $N_{3-6}$ should not be interpreted directly as the exponents of nucleation mechanism. In analysing the correlations between $J_{3}$ or $N_{3-6}$ and sulphuric acid, the determination of the time shift between the quantities is of primary importance.

With activation nucleation mechanism, the main reason for the change in correlation exponent when going from $J_{\text {nuc }}$ to $J_{3}$ and $N_{3-6}$ was found to be the size dependence of the growth rate between nucleation size and $3 \mathrm{~nm}$. This was caused by the condensation of a semi-volatile organic vapour, which gradually starts to condense on particles at size range 1-3 nm. In order to get a linear dependence on sulphuric acid for $J_{3}$ and $N_{3-6}$, i.e. to preserve the dependence of the nucleation rate, the saturation concentration of the organic vapour had to be decreased. With a low saturation concentration, the growth below $3 \mathrm{~nm}$ became faster and was not limited by the Kelvin effect anymore.

Besides the organic vapour condensation, the nucleated cluster size was observed to have a crucial effect on how the correlation with sulphuric acid appears at $3 \mathrm{~nm}$ particle size. Assuming activation nucleation with the nucleated cluster size of $1.5-2 \mathrm{~nm}$, instead of $1 \mathrm{~nm}$, reproduced correlation exponents of 1-2 for $J_{3}$ and $N_{3-6}$. Here the saturation concentration of organic vapour had only a minor effect. According to the present knowledge (Kulmala et al., 2007), the nucleated cluster size of $1.5-2 \mathrm{~nm}$ and a semi-volatile condensable organic vapour with saturation concentration of $10^{5}$ $10^{6} \mathrm{~cm}^{-3}$ would be the most realistic parameter set. Promisingly these yielded a linear, or close to linear, relationship with sulphuric acid, consistently with the field observations.

Simulations with ternary $\mathrm{H}_{2} \mathrm{O}-\mathrm{H}_{2} \mathrm{SO}_{4}-\mathrm{NH}_{3}$ nucleation yielded too steep dependence on sulphuric acid, with regard to observed exponents of 1-2 in field measurements. The correlation exponents were always greater than 4 for both $J_{3}$ and $N_{3-6}$. Therefore it is unlikely that ternary nucleation would be the valid nucleation mechanism for particle formation in atmospheric boundary layer, at least over continental areas. Ternary nucleation may involve some essential characteristics of nucleation, such as the role of ammonia, thus predicting the event occurrence correct at some places (Jung et al., 2008). However, according to our results the actual ternary nucleation rates are not consistent with measurements, but have too strong dependence on sulphuric acid.

It should be noted that also other aerosol dynamical processes, such as varying coagulation sink, may indirectly affect the sulphuric acid correlation during the new particle for- mation event. The effect of coagulation sink becomes more important with high concentrations and high nucleation rates, and it may be the reason why the exponents with ternary nucleation change differently during particle growth compared to activation and kinetic cases.

In summary, the dependence of $J_{3}$ and $N_{3-6}$ on sulphuric acid to the power 1-2, as observed in field measurement data, seems to require the nucleation rate to have a similar dependence on sulphuric acid with $n_{\text {nuc }}=1-2$, i.e. activation or kinetic nucleation. However, aerosol dynamical processes, especially the particle growth, can change the correlation to some extent, and therefore correlations observed at $3 \mathrm{~nm}$ particle size are not necessarily the same as for nucleation rate.

Acknowledgements. Maj and Tor Nessling foundation (project no 2008310) is acknowledged for financial support. This work has been partly funded by EUCAARI (European Integrated project on Aerosol Cloud Climate and Air Quality interactions) No 036833-2.

Edited by: A. Wiedensohler

\section{References}

Anttila, T., Kerminen, V.-M., Kulmala, M., Laaksonen, A., and O'Dowd, C.: Modelling the formation of organic particles in the atmosphere, Atmos. Chem. Phys., 4, 1071-1083, 2004, http://www.atmos-chem-phys.net/4/1071/2004/.

Baker, M. B. and Peter, T.: Small-scale cloud processes and climate, Nature, 451, 299-300, 2008.

Boy, M., Kulmala, M., Ruuskanen, T. M., Pihlatie, M., Reissell, A., Aalto, P. P., Keronen, P., Dal Maso, M., Hellen, H., Hakola, H., Jansson, R., Hanke, M., and Arnold, F.: Sulphuric acid closure and contribution to nucleation mode particle growth, Atmos. Chem. Phys., 5, 863-878, 2005,

http://www.atmos-chem-phys.net/5/863/2005/.

Boy, M., Hellmuth, O., Korhonen, H., Nilsson, E. D., ReVelle, D., Turnipseed, A., Arnold, F., and Kulmala, M.: MALTE - model to predict new aerosol formation in the lower troposphere, Atmos. Chem. Phys., 6, 4499-4517, 2006, http://www.atmos-chem-phys.net/6/4499/2006/.

Fuchs, N. A. and Sutugin, A. G., High dispersed aerosols, in: Topics in Current Aerosol Research (Part 2), edited by: Hidy, G. M. and Brock, J. R., Pergamon, New York, USA, 1-200, 1971.

Gaydos, T. M., Stanier, C. O., and Pandis, S. P.: Modeling of in situ ultrafine atmospheric particle formation in the eastern United States, J. Geophys. Res., 110, D07S12, doi:10.1029/2004JD004683, 2005.

Hari, P. and Kulmala, M.: Station for Measuring Ecosystem Atmosphere Relations (SMEAR II), Boreal Env. Res., 10, 315-322, 2005.

Heaton, K. J., Dreyffus, M. A., Wang, S., and Johnston, M. V.: Oligomers in the early stage of biogenic secondary organic aerosol formation and growth, Environ. Sci. Technol., 41, 61296136, 2007.

Hirsikko, A., Laakso, L, Hõrrak, U., Aalto, P. P., Kerminen, V.M., and Kulmala, M.: Annual and size dependent variation of growth rates and ion concentrations in boreal forest, Boreal Env. Res., 10, 357-369, 2005. 
IPCC (Intergovernmental Panel on Climate Change) Climate Change 2007: The Physical Science Basis. Contribution of Working Group I to the Fourth Assessment Report of the IPCC, http://www.ipcc.ch/ipccreports/ar4-wg1.htm, 2007.

Jung, J. G., Pandis, S. N., and Adams, P. J.: Evaluation of Nucleation Theories in a Sulfur-Rich Environment, Aerosol Sci. Tech., 42, 495-504, doi:10.1080/02786820802187085, 2008.

Kerminen, V.-M., Lehtinen, K. E. J., Anttila, T., and Kulmala, M.: Dynamics of atmospheric nucleation mode particles: a time scale analysis, Tellus, 56B, 135-146, 2004.

Kerminen, V.-M., Lihavainen, H., Komppula, M., Viisanen, Y., and Kulmala, M.: Direct observational evidence linking atmospheric aerosol formation and cloud droplet activation, Geophys. Res. Lett., 32, L14803, doi:10.1029/2005GL023130, 2005.

Komppula, M., Sihto, S.-L., Korhonen, H., Lihavainen, H., Kerminen, V.-M., Kulmala, M., and Viisanen, Y.: New particle formation in air mass transported between two measurement sites in Northern Finland, Atmos. Chem. Phys., 6, 2811-2824, 2006, http://www.atmos-chem-phys.net/6/2811/2006/.

Korhonen, H., Lehtinen, K. E. J., and Kulmala, M.: Multicomponent aerosol dynamics model UHMA: model development and validation, Atmos. Chem. Phys., 4, 757-771, 2004, http://www.atmos-chem-phys.net/4/757/2004/.

Korhonen, H., Kerminen, V.-M., Lehtinen, K. E. J., and Kulmala, M.: CCN activation and cloud processing in sectional aerosol models with low size resolution, Atmos. Chem. Phys., 5, 25612570, 2005, http://www.atmos-chem-phys.net/5/2561/2005/.

Kuang, C., McMurry, P. H., McCormick, A. V., and Eisele, F.: Dependence of nucleation rates on sulfuric acid vapor concentration in diverse atmospheric locations, J. Geophys. Res., 113, D10209, doi:10.1029/2007JD009253, 2008.

Kulmala, M., Kerminen, V.-M., and Laaksonen, A.: Simulations on the effect of sulphuric acid formation on atmospheric aerosol concentrations, Atmos. Environ., 29, 377-382, 1995.

Kulmala, M., Toivonen, A., Mäkelä, J., and Laaksonen, A.: Analysis of the growth of nucleation mode particles observed in Boreal forest, Tellus, 50B, 449-462, 1998.

Kulmala, M., Vehkamäki, H., Petäjä, T., Dal Maso, M., Lauri, A., Kerminen, V.-M., Birmili, W., and McMurry, P. H.: Formation and growth rates of ultrafine atmospheric particles: A review of observations, J. Aerosol Sci., 35, 143-176, 2004a.

Kulmala, M., Suni, T., Lehtinen, K. E. J., Dal Maso, M., Boy, M., Reissell, A., Rannik, Ü., Aalto, P., Keronen, P., Hakola, H., Bäck, J., Hoffmann, T., Vesala, T., and Hari, P.: A new feedback mechanism linking forests, aerosols, and climate, Atmos. Chem. Phys., 4, 557-562, 2004b,

http://www.atmos-chem-phys.net/4/557/2004/.

Kulmala, M., Kerminen, V.-M., Anttila, T., Laaksonen, A., and O'Dowd, C. D.: Organic aerosol formation via sulphate cluster activation, J. Geophys. Res., 109, D04205, doi:10.1029/2003JD003961, 2004c.

Kulmala, M., Lehtinen, K. E. J., and Laaksonen, A.: Cluster activation theory as an explanation of the linear dependence of the formation rate of $3 \mathrm{~nm}$ particles and sulphuric acid concentrations, Atmos. Chem. Phys., 6, 787-793, 2006, http://www.atmos-chem-phys.net/6/787/2006/.

Kulmala, M., Riipinen, I., Sipilä, M., Manninen, H. E., Petäjä, T., Junninen, H., Dal Maso, M., Mordas, G., Mirme, A., Vana, M., Hirsikko, A., Laakso, L., Harrison, R. M., Hanson, I., Leung,
C., Lehtinen, K. E. J., and Kerminen, V.-M.: Toward Direct Measurement of Atmospheric Nucleation, Science, 318, 89-92, 2007.

Kulmala, M. and Kerminen, V.-M.: On the formation and growth of atmospheric nanoparticles, Atmos. Res., 90, 132-150, 2008.

Laakso, L., Anttila, T., Lehtinen, K. E. J., Aalto, P. P., Kulmala, M., Hõrrak, U., Paatero, J., Hanke, M., and Arnold, F.: Kinetic nucleation and ions in boreal forest particle formation events, Atmos. Chem. Phys., 4, 2353-2366, 2004,

http://www.atmos-chem-phys.net/4/2353/2004/.

Laaksonen, A., Hamed, A., Joutsensaari, J., Hiltunen, L, Cavalli, F., Junkermann, W., Asmi, A., Fuzzi, S., and Facchini, M. C.: Cloud condensation nucleus production from nucleation events at a highly polluted region, Geophys. Res. Lett., 32, L06812, doi:10.1029/2004GL022092, 2005.

Lehtinen, K. E. J. and Kulmala, M.: A model for particle formation and growth in the atmosphere with molecular resolution in size, Atmos. Chem. Phys., 3, 251-257, 2003,

http://www.atmos-chem-phys.net/3/251/2003/.

Limbeck, A., Kulmala, M., and Puxbaum, H.: Secondary organic aerosol formation in the atmosphere via heterogenous reaction of gaseous isoprene on acidic particles, Geophys. Res. Lett., 30, 1996, doi:10.1029/2003GL017738, 2003.

McMurry, P. and Friedlander, S. K.: New particle formation in the presence of an aerosol, Atmos. Environ., 13, 1635-1651, 1979.

McMurry, P. H.: New partcle formation in the presence of an aerosol: Rates, time scales and sub-0.01 um size distributions, J. Colloid Interface Sci., 95, 72-80, 1983.

McMurry, P. H., Fink, M. A., Sakurai, H., Stolzenburg, M. R., Mauldin, L., Moore, K., Smith, J. N., Eisele, F. L., Sjostedt, S., Tanner, D., Huey, L. G., Nowak, J. B., Edgerton, E., and Voisin, D.: A criterion for new particle formation in the sulfur-rich Atlanta atmosphere, J. Geophys. Res., 110, D22S02, doi:10.1029/2005JD005901, 2005.

Napari, I., Noppel, M., Vehkamäki, H., and Kulmala, M.: An improved model for ternary nucleation of sulfuric acid-ammoniawater, J. Chem. Phys. 116, 4221, 2002a.

Napari, I., Noppel, M., Vehkamäki, H., and Kulmala, M.: Parametrization of ternary nucleation rates for $\mathrm{H}_{2} \mathrm{SO}_{4}-$ $\mathrm{NH}_{3}-\mathrm{H}_{2} \mathrm{O}$ vapors, J. Geophys. Res., 107(D19), 4381, doi:10.1029/2002JD002132, 2002b.

Napari, I., Makkonen, R., Kulmala, M., and Vehkamäki, H.: Parameterization of ammonia and water content of atmospheric droplets with fixed number of sulfuric acid molecules, Atmos. Res., 82, 514-522, 2006.

Penner, J. E., Quaas, J., Storelvmo, T., Takemura, T., Boucher, O., Guo, H., Kirkevåg, A., Kristjansson, J. E., and Seland, $\varnothing$ : Model intercomparison of indirect aerosol effects, Atmos. Chem. Phys., 6, 3391-3405, 2006, http://www.atmos-chemphys.net/6/3391/2006/.

Rannik, Ü., Aalto, P., Keronen, P., Vesala, T., and Kulmala, M.: Interpretation of aerosol particle fluxes over a pine forest: Dry deposition and random errors, J. Geophys. Res., 108(D17), 4544, doi:10.1029/2003JD003542, 2003.

Riipinen, I., Sihto, S.-L., Kulmala, M., Arnold, F., Dal Maso, M., Birmili, W., Saarnio, K., Teinilä, K., Kerminen, V. M., Laaksonen, A., and Lehtinen, K. E. J.: Connections between atmospheric sulphuric acid and new particle formation during QUEST III-IV campaigns in Heidelberg and Hyytiälä, Atmos. Chem. 
Phys., 7, 1899-1914, 2007,

http://www.atmos-chem-phys.net/7/1899/2007/.

Rosenfeld, D.: Aerosol, clouds, and climate, Science, 312, 13231324, 2006.

Sihto, S.-L., Kulmala, M., Kerminen, V.-M., Dal Maso, M., Petäjä, T., Riipinen, I., Korhonen, H., Arnold, F., Janson, R., Boy, M., Laaksonen, A., and Lehtinen, K. E. J.: Atmospheric sulphuric acid and aerosol formation: Implications from atmospheric measurements for nucleation and early growth mechanisms, Atmos. Chem. Phys., 6, 4079-4091, 2006, http://www.atmos-chem-phys.net/6/4079/2006/.

Spracklen, D. V., Carslaw, K. S., Kulmala, M., Kerminen, V.-M., Mann, G. W., and Sihto, S.-L.: The contribution of boundary layer nucleation events to total particle concentrations on regional and global scales, Atmos. Chem. Phys., 6, 5631-5648, 2006, http://www.atmos-chem-phys.net/6/5631/2006/.

Spracklen, D. V., Carslaw, K. S., Kulmala, M., Kerminen, V.-M., Sihto, S.-L., Riipinen, I., Merikanto, J., Mann, G. W., Chipperfield, M. P., Wiedensohler, A., Birmili, W., and Lihavainen, H.: Contribution of particle formation to global cloud condensation nuclei concentrations, Geophys. Res. Lett., 35, L06808, doi:10.1029/2007GL033038, 2008.

Tunved, P., Hansson, H.-C., Kerminen, V.-M., Ström, J., Dal Maso, M., Lihavainen, H., Viisanen, Y., Aalto, P. P., Komppula, M., and Kulmala, M.: High natural aerosol loading over boreal forests, Science, 312, 261-263, 2006.
Vehkamäki, H., Kulmala, M., Napari, I., Lehtinen, K. E. J., Timmreck, C., Noppel, M., and Laaksonen, A.: An improved parameterization for sulfuric acid-water nucleation rates for tropospheric and stratospheric conditions, J. Geophys. Res., 107, 4622, 2002.

Weber, R. J., Marti, J. J., McMurry, P. H., Eisele, F. L., Tanner, D. J., and Jefferson, A.: Measured atmospheric new particle formation rates: implications for nucleation mechanisms, Chem. Eng. Comm., 151, 53-64, 1996.

Weber, R. J., Marti, J. J., McMurry, P. H., Eisele, F. L., Tanner, D. J., and Jefferson A.: Measurements of new particle formation and ultrafine particle growth rates at a clean continental site, J. Geophys. Res., 102, 4375-4385, 1997.

Wehner, B., Petäjä, T., Boy, M., Engler, C., Birmili, W., Tuch, T. Wiedensohler, A., and Kulmala, M.: The contribution of sulfuric acid and non-volatile compounds on the growth of freshly formed atmospheric aerosols, Geophys. Res. Lett., 32, L17810, doi:10.1029/2005GL023827, 2005.

Yu, F.: From molecular clusters to nanoparticles: Secondgeneration ion-mediated nucleation model, Atmos. Chem. Phys., 6, 5193-5211, 2006, http://www.atmos-chemphys.net/6/5193/2006/.

Zhang, K. M. and Wexler, A. S: A hypothesis for growth of fresh atmospheric nuclei, J. Geophys. Res., 107(D21), 4577, doi:10.1029/2002JD002180, 2002. 